\title{
Mass Discrimination During MC-ICPMS \\ Isotopic Ratio Measurements: Investigation \\ by Means of Synthetic Isotopic Mixtures \\ (IRMM-007 Series) and Application \\ to the Calibration of Natural-Like Zinc Materials \\ (Including IRMM-3702 and IRMM-651)
}

\author{
Emmanuel Ponzevera, Christophe R. Quétel, Michael Berglund, \\ and Philip D. P. Taylor \\ European Commission Joint Research Center, Institute for Reference Materials and Measurements (IRMM), \\ Geel, Belgium
}

Peter Evans

LGC, Teddington, United Kingdom

Robert D. Loss

Department of Imaging and Applied Physics, Curtin University of Technology, Perth, Australia

Giuseppino Fortunato

Materials Science and Technology (EMPA), St. Gallen, Switzerland

A long known way of anchoring isotope ratio values to the SI system is by means of gravimetrically prepared isotopic mixtures. Thermal ionization mass spectrometry (TIMS) is the traditionally associated measurement technique, but multi-collector double focusing inductively coupled plasma (MCICP)-MS now appears to be an attractive alternative. This absolute calibration strategy necessitates that mass discrimination effects remain invariant in time and across the range of isotope ratios measured. It is not the case with MC-ICPMS and the present work illustrates, in the case of $\mathrm{Zn}$ isotopic measurements carried out using locally produced synthetic Zn isotope mixtures (IRMM-007 series), how this calibration strategy must be adjusted. First, variation in mass discrimination effects across the measurement sequence is propagated as an uncertainty component. Second, linear proportionality during each individual measurement between normalized mass discrimination and the average mass of the isotope ratios is used to evaluate mass discrimination for the ratios involving low abundance isotopes. Third, linear proportionality between mass discrimination and the logarithm of the isotope ratio values for $n\left({ }^{67} \mathrm{Zn}\right) / n\left({ }^{64} \mathrm{Zn}\right)$ and $n\left({ }^{68} \mathrm{Zn}\right) / n\left({ }^{64} \mathrm{Zn}\right)$ in the mixtures is used iteratively to evaluate mass discrimination for the same ratios in the isotopically enriched materials. Fourth, ratios in natural-like materials (including IRMM-3702 and IRMM-651) are calibrated by external bracketing using the isotopic mixtures. The relative expanded uncertainty $(k=2)$ estimated for $n\left({ }^{68} \mathrm{Zn}\right) / n\left({ }^{64} \mathrm{Zn}\right)$ and $n\left({ }^{67} \mathrm{Zn}\right) / n\left({ }^{64} \mathrm{Zn}\right)$ ratio values in the synthetic isotopic mixtures and the natural-like zinc samples was in the range of 0.034 to $0.048 \%$. The uncertainty on the weighing $(0.01 \%, k=1)$ was the largest contributor to these budgets. The agreement between these results and those obtained with a single detector TIMS and with another MC-ICPMS further validated this work. The absolute isotope ratio values found for IRMM-3702-material also proposed as "delta 0 " for $\delta$-scale isotopic measurements - are $n\left({ }^{66} \mathrm{Zn}\right) /$ $n\left({ }^{64} \mathrm{Zn}\right)=0.56397(30), n\left({ }^{67} \mathrm{Zn}\right) / n\left({ }^{64} \mathrm{Zn}\right)=0.082166(35), n\left({ }^{68} \mathrm{Zn}\right) / n\left({ }^{64} \mathrm{Zn}\right)=0.37519(16)$, and $n\left({ }^{70} \mathrm{Zn}\right) /$ $n\left({ }^{64} \mathrm{Zn}\right)=0.012418(23)$. The derived $\mathrm{Zn}$ atomic weight value $\mathrm{A}_{\mathrm{r}}(\mathrm{Zn})=65.37777(22)$ differs significantly from the current IUPAC value by Chang et al. [1]. Remeasurement, with isotopic mixtures from the IRMM-007 series, of the $\mathrm{Zn}$ isotope ratios in the same Chang et al. [1] material have revealed large systematic differences $(1.35(27) \%$ per atomic mass unit) that suggest unrecognized measurement biases in their results. (J Am Soc Mass Spectrom 2006, 17, 1412-1427) (C) 2006 American Society for Mass Spectrometry

Published online July 28, 2006

Address reprint requests to Dr. C. R. Quétel, European Commission Joint Research Center, Institute for Reference Materials and Measurements, Retieseweg 111, B-2440 Geel, Belgium. E-mail: christophe.quetel@ec.europa.eu
Z inc is important to human metabolism. Measuring $\mathrm{Zn}$ isotope ratios in urine or faeces samples and monitoring the associated isotopic fractionation effects is used to follow the way the human body absorbs Zn [2, 3]. Zn also has applica- 
tions as an isotopic tracer in geochemistry and environmental studies [4], where it is employed to understand geological processes and to localize sources and pathways of pollutants in nature.

In 1997, an IUPAC technical report [5] (column 6, footnote F) from the Commission on Atomic Weights and Isotopic Abundance considered that $\mathrm{Zn}$ was one of the many elements for which isotopic composition had not yet been measured in a calibrated manner and reported as such. Thus, the IUPAC value based on Rosman [6] and Marinenko and Foley [7] results was recently changed [8] to the value of 65.409 (4) obtained by Chang et al. [1] in 2001 from calibrated measurements using gravimetrically prepared isotope mixtures. In 2002, Tanimizu et al. [9] also reported the production and use of $\mathrm{Zn}$ isotope mixtures for identical purposes.

These mixtures are not widely available and there are no internationally accepted isotopic certified reference materials of zinc despite the growing interest for low uncertainty $\mathrm{Zn}$ isotopic measurements. Results of isotope ratio measurements are often reported in a $\delta$-scale relatively to the results obtained for a $\mathrm{Zn}$ standard [4, 10-12] and, obviously, comparing $\delta$ values from different studies may be impossible if the same standard were not used by the different laboratories. In addition, it is desirable to have these materials available in liquid form to avoid the risk of isotopic heterogeneity with standards in solid form (metal shots) [13]. In 2002, the same IUPAC commission concluded that the preparation of isotopic reference materials of zinc would improve comparability of isotope-ratio measurements among laboratories [14].

For these reasons the Institute for Reference Materials and Measurements (IRMM, Geel, Belgium), from the European Commission Joint Research Center, is distributing a natural-like zinc material as a solution, IRMM-3702, to serve as common "delta 0" material (available upon request). Additionally and in an attempt to insure traceability to the SI system of units in the shortest way possible for all our $\mathrm{Zn}$ measurement results, we have also produced a series of candidate $\mathrm{Zn}$ isotopic certified reference materials (ICRM). These include natural-like $\mathrm{Zn}$ solutions, gravimetric $\mathrm{Zn}$ isotope mixtures, and $\mathrm{Zn}$ isotope spikes, which we used to calibrate multiple collector inductively coupled plasma mass spectrometry (MCICPMS) isotopic measurements of natural-like zinc samples.

Since the beginning of the 1960s, thermal ionization mass spectrometry (TIMS) has almost always been the technique associated with isotopic calibration work based on the preparation and the use of multiple synthetic isotope mixtures [15-18]. Rosman [6] and Chang et al. [1] used TIMS for their measurements, whereas Tanimizu et al. [9] employed MCICPMS. This calibration strategy required highly repeatable isotope ratio measurements and constancy of mass discrimination effects over time and over the range of isotope ratio values covered by the isotopic mixtures. Mass discrimination during measurements can be expressed as the ratio between the "true" and the measured values of a given isotope ratio, e.g., the so-called $K$ factor (eq 1, Table 1).

MC-ICPMS was introduced less than 15 years ago [19], and specific aspects such as the interpretation of mass discrimination effects and the way of correcting for them are still heavily debated. The semi-empirical models proposed by Russel et al. [20] originally for TIMS measurements were tried out with MC-ICPMS measurements. The exponential model (eq 2, Table 1), often preferred over the linear or the power functions, is considered to be acceptable in the absence of a better alternative and despite important operational differences between the two techniques.

According to Freedman [21], mass discrimination during MC-ICPMS measurements mostly results from the combination of two processes taking place in the instrument interface. First, at the rear of the sample cone (sampler), a supersonic expansion occurs, resulting in lower transport efficiency for the lighter ions; then after the skimmer cone, the extraction voltage repels the electrons from the ion beam, creating space charge effects (electrostatic interactions between positively charged ions) that preferentially affect the lighter ions. These two-stage physical processes are thought to be equally responsible for the mass discrimination amplitude that in the case of the exponential law results in a value of $\sim 2$ for the normalized mass discrimination factor $\varepsilon$. However, mass discrimination effects can easily and significantly change in amplitude during MC-ICPMS measurements. Post-sampler expansion conditions depend on the quality of the interface vacuum (e.g., driven by the rotary pump efficiency, the samplerfront plate air tightness, the sampler orifice diameter, etc.). Besides, space charge effects depend on the density and the composition of the ion beam (linked to sample matrix composition and concentration, the nature of the analyte, the extraction voltage, etc.). Interventions by the analyst (hardware maintenance, tuning) and/or instrumental instability in the interface region can explain the day-to-day variability reported by Maréchal et al. [10]. Mass discrimination effects can also change during measurement sessions and are not necessarily constant over a given range of isotope ratio values. These issues are not well understood and only rarely addressed. A fortiori, the necessary adjustments of the synthetic isotope mixtures theory to the reality of MC-ICPMS have not yet been discussed in the literature.

This paper, through a specific application to $\mathrm{Zn}$ calibration work, reviews these critical aspects and proposes a new and validated approach adapted specifically to MC-ICPMS. We also review the differences between the $\mathrm{Zn}$ atomic weight values published 
Table 1. Equations used in this study

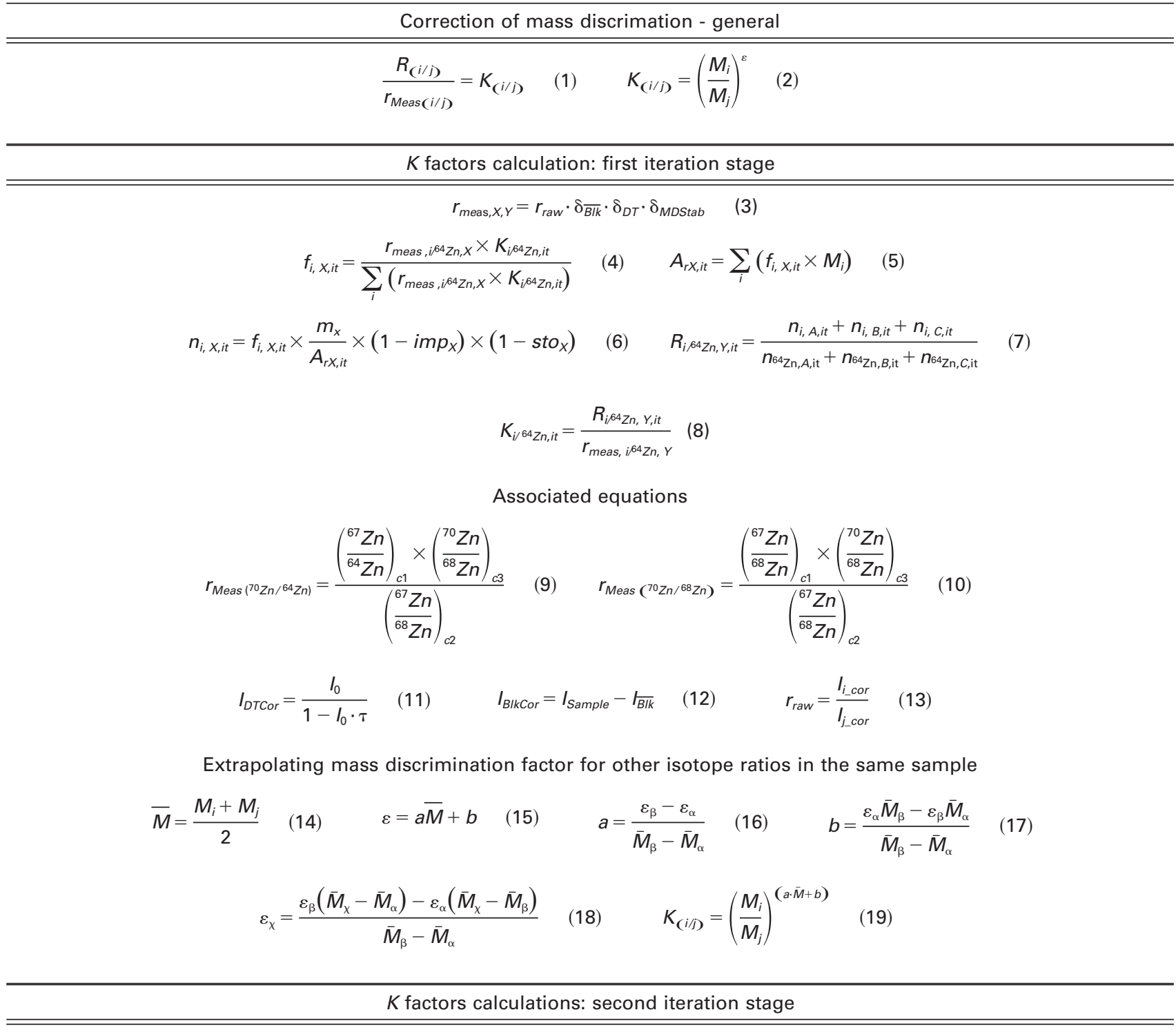

Extrapolating mass discrimation factor for the same isotope ratios in other samples

$K_{68 Z n 64 Z n, X}=d_{1} \cdot \log \left(R_{68 Z n 64 Z n, X}\right)+e_{1} \quad(20) \quad K_{67 Z n 64 Z n, X}=d_{2} \cdot \log \left(R_{67 Z n 64 Z n, X}\right)+e_{2}$

Absolution calibration of measurement on natural-like zinc materials

$$
\begin{gathered}
R_{\text {IRMM -651 }}=\frac{1}{4} \cdot\left(\left(\frac{R_{M 3}}{r_{M 3}}+\frac{R_{M 4}}{r_{M 4}}\right) \cdot r_{I R M M-651 \_1}+\left(\frac{R_{M 5}}{r_{M 5}}+\frac{R_{M 6}}{r_{M 6}}\right) \cdot r_{I R M M-651 \_2}\right) \\
R_{I M-1009}=\frac{1}{2}\left(\frac{R_{M 5}}{r_{M 5}}+\frac{R_{M 6}}{r_{M 6}}\right) \cdot r_{I M-1009} \\
R_{I R M M-3702}=\frac{1}{6} \cdot \sum_{s=1}^{3}\left(\frac{R_{\text {IRMM-651 }}}{r_{\text {IRMM-651_s }}}+\frac{R_{\text {IRMM-651 }}}{r_{\text {IRMM } 651 \_s+1}}\right) \cdot r_{I R M M-3702 \_s}
\end{gathered}
$$


Table 1. (Continued) Parameters and indexes used in eqs 1 to 24, Table 1

\begin{tabular}{|c|c|c|c|}
\hline Parameter & & Index & \\
\hline$R$ & Corrected isotope ratio & $\mathrm{i}, \mathrm{j}$ & Different $\mathrm{Zn}$ isotopes: ${ }^{64} \mathrm{Zn},{ }^{66} \mathrm{Zn},{ }^{67} \mathrm{Zn},{ }^{68} \mathrm{Zn},{ }^{70} \mathrm{Zn}$ \\
\hline$r$ & Measured isotope ratio & meas & $\begin{array}{l}\text { Raw measured isotope ratio corrected for BIk, DT } \\
\text { and MDstab }\end{array}$ \\
\hline K & Mass discrimination factor & $\mathrm{X}$ & $\begin{array}{l}\text { Enriched Materials: IRMM-652 (A), IRMM-653 (B) } \\
\text { and IRMM-654 (C) }\end{array}$ \\
\hline$M$ & Atomic mass $\left(\mathrm{g} \mathrm{mol}^{-1}\right)$ & Y & Isotope mixtures M1 to M6 \\
\hline$\varepsilon$ & Normalized mass discrimination factor & raw & Raw measured isotope ratio \\
\hline$\delta$ & $\begin{array}{l}\text { Unity multiplicative factors carrying } \\
\text { uncertainty associated to corrections } \\
\text { for various effects }\end{array}$ & $\overline{B I k}$ & Correction for average procedural blank \\
\hline$f$ & Isotopic abundance & DT & Correction for ion counter dead time effect \\
\hline$A_{r}$ & Atomic weight $\left(\mathrm{g} \mathrm{mol}^{-1}\right)$ & MDStab & Correction for variability of mass discrimination in time \\
\hline$n$ & Number of moles (mol) & it & Iteration step \\
\hline$m$ & Weighed mass $(\mathrm{g})$ & $c_{x}$ & Cycle number in dynamic acquisition $(X=1,2$ or 3$)$ \\
\hline imp & Relative impurity amount & $\hat{\operatorname{cor}}$ & Corrected effect \\
\hline sto & Relative non-stoichiometry & $\alpha, \beta$ & Known isotope ratios \\
\hline$\tau$ & Ion counter dead time value (s) & $\chi$ & Unknown isotope ratio \\
\hline I & Signal intensity & o & Before correction for dead time effect \\
\hline$a, d_{1}, d_{2}$ & Slopes & & \\
\hline$b, e_{1}, e_{2}$ & Intercepts & & \\
\hline
\end{tabular}

over the last 60 years and recommend a new calibrated atomic weight for this element.

\section{Absolute Calibration by Means of Gravimetrically Prepared Isotopic Mixtures}

Comparability can be achieved by making measurements traceable to a common and long-standing reference system with combined uncertainty statements to demonstrate the results' reliability. Traceability can be visualized as a chain or a combination of chains, between a measurement result and unit references in which each link is a mathematical expression. The complete mathematical model describes the best understanding of the measurement process. The uncertainties associated with each component must be realistically estimated and budgeted, using this mathematical model, to determine the combined uncertainty of the measurement result [22]. Mass discrimination is a major cause of bias during mass spectrometry measurement and results from the difference in generation and/or transmission of ions between isotopes as a function of their mass. It can be evaluated from the measurement of an isotope ratio, the value of which is known within explicit uncertainty (eqs 1 and 2, Table 1).

Correction for mass discrimination during ICPMS measurements is explained elsewhere [23]. Using ICRMs according to well described equations provides the necessary means to establish traceability of the measurement results to the reference values associated with these ICRMs. Absolute calibration consists in establishing this relationship. A powerful way to establish the primary link to the SI is via a reference to the $\mathrm{Kg}$. This is achieved by mixing together gravimetrically isotopically enriched materials. Measuring isotopic ratio values of these mixtures and comparing results with the gravimetrical values enables the magnitude of the mass discrimination induced by the mass spectrometer to be determined. With TIMS measurements, mass discrimination is substantially less and also considered to be better understood and easier to monitor than that obtained for ICPMS measurements. Thus, constancy of the mass discrimination over a given range of isotope ratio values is also less critical for TIMS than for ICPMS measurements.

The usual steps of an absolute calibration procedure by means of gravimetric isotopic mixtures were described in previous studies [15-18]. Briefly, the starting isotopically enriched materials must be purified to minimize the impact of the correction for impurity content on the combined uncertainty evaluations. Weighing data may also have to be corrected for possible non-stoichiometry of the weighed element species. Usually, several isotopic mixtures are prepared to cover the range of isotope ratio values that the actual samples to be measured will span (typically from $\sim 0.01$ to 100 ). The isotope ratios of the enriched materials and the gravimetrically prepared mixtures are measured successively with the same mass spectrometer and the results are compared with the weighing data through a mathematical iterative process. The equations used for the evaluation of the mass discrimination effect by iteration and the determination of the associated combined uncertainty estimation are detailed in Table 1 (eqs 3 to 8 and associated).

\section{Experimental}

\section{Instrumentation}

This study was carried out on a Nu Plasma $500(\mathrm{Nu}$ Instruments, Wrexham, UK), a Nier-Johnson-type double focussing magnetic sector MC-ICPMS, 
equipped with 12 Faraday cups mounted on a fixed array and three ion counters. Following dispersion by the magnetic field, the individual ion beams are steered into the appropriate detectors using a set of "zoom" lenses [24].

The results of these measurements were compared with those obtained on two other mass spectrometers: a Neptune MC-ICPMS [25] (Thermo Finnigan, Bremen, Germany) operated at LGC Ltd. (Teddington, UK) and a NBS-type single collector TIMS [17] in use at IRMM.

Measurements of impurity amounts in the refined enriched materials were carried out at EMPA (Materials Science and Technology, St. Gallen, Switzerland) with an Axiom MC-ICPMS (Thermo Elemental, formerly VG, Winsford, UK) operated in single detection mode [26].

\section{Materials and Samples}

Ten isotopic mixtures (IRMM-007/1 to IRMM-007/10 referred to hereafter as M1 to M10) were gravimetrically prepared using purified enriched materials in ${ }^{64} \mathrm{Zn}(\sim 99.3 \%),{ }^{67} \mathrm{Zn}(\sim 91.8 \%)$, and ${ }^{68} \mathrm{Zn}(\sim 99.1 \%)$ purchased from Cofermin Rohstoffe GmbH (Essen, Germany) referred to hereafter as IRMM-652, IRMM653, and IRMM-654, respectively. The purification of the starting materials by vacuum distillation was performed at EMPA according to in-house standard operating procedures [27, 28]. The refined materials were stored in acid-cleaned quartz ampoules filled with Ar to prevent oxidation.

Different natural-like $\mathrm{Zn}$ samples were calibrated with the prepared isotopic mixtures during this study: IRMM-651 and IRMM-3702 purchased from Alfa Aesar (lot no. I12G04 and lot no. 10759, Ward Hill, MA) and IM-1009 corresponding to Sample 2 in Chang et al. [1]. These samples were all available in liquid form in sealed quartz ampoules. IRMM-3702 was prepared to serve as common "delta 0 " material. It is foreseen that IRMM-651 and the isotopic mixtures IRMM-007/1 to IRMM-007/10 will eventually become commercially available as ICRMs [29]. The IRMM-072/9 uranium ICRM [16] was used for the evaluation of the ion counter dead time.

All samples were prepared in $2 \% \mathrm{HNO}_{3}$ matrix, and appropriate dilutions were made with Milli-Q deionized water (Millipore, Bedford, MA) and ultra pure concentrated nitric acid supplied from J. T. Baker $(70 \%$, Ultrex, Phillipsburg, NJ).

\section{Preparation of the $\mathrm{Zn}$ Isotope Mixtures}

Purified enriched Zn materials were mixed gravimetrically by metrological weighing specialists from IRMM in a humidity and temperature controlled area using substitution measurements (no impact from the nonlinearity of the balance) against operational mass standards traceable to the $\mathrm{Kg}$ in the shortest possible comparative way [30]. Buoyancy correction was implemented although it appeared to be a negligible source of uncertainty.

All weighing of the vacuum distilled enriched zinc pieces took place in a glove box originally flushed with argon. Argon was also supplied permanently from the top of the glove box at low flow-rate and the steady-state of the argon atmosphere was monitored from the mass variations (within $2 \mu \mathrm{g}$ ) of an aluminium piece (chosen for its low density and stability). The density of the argon in the glove box was determined from the comparison of the masses obtained for this aluminium piece in this argon atmosphere and under well-known normal air density conditions. During the weighing procedure, care was taken not to disturb the argon density by reducing movements to a minimum.

The three isotopically enriched $\mathrm{Zn}$ materials were weighed as metal in small glass boats, introduced into PTFE bottles and mixed with $\mathrm{HNO}_{3}$ for dissolution purposes to produce three separate mother solutions, IRMM-6052, IRMM-6053, and IRMM-6054 (enriched in ${ }^{64} \mathrm{Zn},{ }^{67} \mathrm{Zn}$, and ${ }^{68} \mathrm{Zn}$, respectively). With these precautions, no correction for stoichiometry was deemed necessary for the solid weighing results.

These bottles were transferred to an ultra-clean laboratory facility to perform the next series of weighing. A blend of IRMM-6053 and IRMM-6054 was prepared and, finally, weighed aliquots of IRMM- 6052 and of the mixture IRMM-6053/6054 were mixed to create the $\mathrm{Zn}$ isotope mixtures. Weighing data are compiled in Table 2.

Impurity amounts of the $\mathrm{Zn}$ enriched materials were evaluated by external calibration using the Axiom in the HR-ICPMS mode. Thirty-five elements were investigated. The standard uncertainty for every measured element was taken as $30 \%$ of the measured concentration or of the determined detection limit. Eventually, the cumulated mass fractions $\left(\mathrm{g} \mathrm{g}^{-1}\right)$ were found to be $1.49 \pm 3.77(k=1) 10^{-5}, 6.54$ $\pm 3.62(k=1) 10^{-5}$, and $6.71 \pm 3.64(k=1) 10^{-5}$ for IRMM-652, IRMM-653, and IRMM654 solutions, respectively. This conservative approach was chosen to cover for the elements not investigated, considering besides, that all dissolved gases had been removed from the raw metallic materials at the distillation stage.

\section{Measurements with the Nu Plasma}

Two methods of acquisition were designed to cover the range of isotope ratios to be measured (Figure 1a). For the natural-like $\mathrm{Zn}$ samples, the isotope mixtures and IRMM-653, only one cycle was necessary. Measurement of $r_{\text {Meas }(70 \mathrm{Zn} / 64 \mathrm{Zn})}$ in IRMM-652 and $r_{\text {Meas }(70 \mathrm{Zn} / 68 \mathrm{Zn})}$ in IRMM-654 necessitated the combination of an ion counter (IC0) and Faraday cups (eqs 9 and 10, Table 1) and three consecutive cycles were necessary (dynamic acquisition, with magnet jumps 
Table 2. Weighing data (in g) for the preparation of enriched materials and isotope mixtures solutions. All weighing were carried out on liquid samples except for the preparation of mother solutions from solid materials (Step 1). All uncertainties indicated are expanded uncertainty $\mathrm{U}=k \cdot \mathrm{u}_{\mathrm{c}}$ where $\mathrm{u}_{\mathrm{c}}$ is the combined standard uncertainty. They are given in parentheses and include a coverage factor $k=2$. They apply to the last digits of the value.

\begin{tabular}{|c|c|c|c|c|}
\hline Step 1 & $\begin{array}{l}\text { Mother solutions } \\
\text { Metal } \\
\text { Diluent+Metal }\end{array}$ & $\begin{array}{r}\text { IRMM-6052 } \\
0.206006(20) \\
500.869(50)\end{array}$ & $\begin{array}{l}\text { IRMM-6053 } \\
0.032780(10) \\
507.304(52)\end{array}$ & $\begin{array}{l}\text { IRMM6054 } \\
0.086392(10) \\
500.796(50)\end{array}$ \\
\hline Step 2 & $\begin{array}{l}\text { Mixture IRMM-6053/6054 } \\
\text { Aliquot }\end{array}$ & $\begin{array}{l}\text { IRMM-6053 } \\
380.854(76)\end{array}$ & $\begin{array}{l}\text { IRMM-6054 } \\
127.091(26)\end{array}$ & \\
\hline Step 3 & $\begin{array}{l}\text { Isotope Mixtures } \\
\text { IRMM-007/1 } \\
\text { IRMM-007/2 } \\
\text { IRMM-007/3 } \\
\text { IRMM-007/4 } \\
\text { IRMM-007/5 } \\
\text { IRMM-007/6 }\end{array}$ & $\begin{array}{c}\text { IRMM-6052 } \\
99.923(20) \\
56.0660(102) \\
29.0190(58) \\
19.9980(40) \\
10.0055(20) \\
9.0147(18)\end{array}$ & Mixtur & $3 / 6054$ \\
\hline
\end{tabular}

between cycles). Cycle 1 was common to both methods. Faraday cup F11 was physically moved in front of the ion counter IC2 (as previously done for uranium measurements [23], to allow for the collection of ${ }^{68} \mathrm{Zn}^{+}$during cycle 3 .

The dead time (eq 11, Table 1) on IC0 was evaluated using IRMM-072/9 according to method 2 described in reference [31]. A value of $\tau=7 \pm 4(k=2)$ ns was obtained.

The parameters of the zoom lenses were optimized for each cycle using a natural-like $\mathrm{Zn}$ solution. Systematically, following the initial $2 \mathrm{~h}$ of warm-up, the instrument was tuned for ion transmission, and the peak shape and alignment were optimized for each cycle (see parameters in Table 3). There was no interference of ${ }^{64} \mathrm{Ni}^{+}$(despite the use of standard Ni cones), ${ }^{70} \mathrm{Ge}^{+}$on ${ }^{64} \mathrm{Zn}^{+},{ }^{70} \mathrm{Zn}^{+}$respectively $\left({ }^{60} \mathrm{Ni}^{+}\right.$, and ${ }^{74} \mathrm{Ge}^{+}$signals indistinguishable from instrumental background). Zinc hydride formation rate was found at mass $65\left(\mathrm{H}^{64} \mathrm{Zn}^{+}\right)$to be always below $0.001 \%$ (negligible, also demonstrating the absence of significant amounts of $\mathrm{Cu}$ in the samples). No autosampler was used during the experiments, and the sample probe was always rinsed twice consecutively (with two different solutions of $2 \% \mathrm{HNO}_{3}$ ). To ensure the absence of cross contamination effects, it was necessary to rinse with $2 \% \mathrm{HNO}_{3}$ for $15 \mathrm{~min}$ between every sample. The signals recorded on peaks in the last $5 \mathrm{~min}$ of each rinse period were averaged and subtracted to the following sample signals (eq 12, Table 1). This way, as the diluted nitric acid used for sample dilutions and the wash out solutions originated from the same batch, samples could be corrected for "chemical" blank, sample to sample memory effects, and instrumental background at the same time (combination hereafter referred as "procedural blank").

The measurements were performed over two consecutive days. A preamplifier gain calibration was performed at the beginning of each day's session [the maximum relative standard deviation, (RSD), for gain factors values was $0.0005 \%$, for two consecutive series of acquisitions during $30 \mathrm{~min}]$. The analytical sequence applied is described in Figure 1b.

\section{Data Treatment and Uncertainty Estimation}

All isotope ratio calculations were carried out in MS Excel (Microsoft, Redmond, WA). There were 30 measurements (3 blocks, 10 repeats) per cycle. Each repeat was corrected for an average blank, and a 2- $\sigma$ outlier test was applied for

(a)

\begin{tabular}{|c|c|c|c|c|c|c|c|c|c|c|c|c|c|c|c|c|c|c|c|c|c|c|c|}
\hline & F0 & F1 & F2 & F3 & $\mathrm{F} 4$ & F5 & $\mathrm{F} 6$ & F7 & F8 & ICO & F9 & IC1 & F10 & F11 & & \begin{tabular}{|l|} 
Quad1 \\
\end{tabular} & Quad2 & Lin1 & Lin2 & Lincor & \begin{tabular}{|l|} 
Cubic \\
\end{tabular} & \begin{tabular}{|l|} 
Q13corr \\
\end{tabular} & Q14corr \\
\hline Cycle 1 & & ${ }^{70} \mathrm{Zn}$ & & & ${ }^{68} \mathrm{Zn}$ & & ${ }^{67} \mathrm{Zn}$ & & ${ }^{66} \mathrm{Zn}$ & & $\mathrm{H}^{64} \mathrm{Zn}$ & & ${ }^{64} \mathrm{Zn}$ & & $x$ & \begin{tabular}{|l|}
-67.5 \\
\end{tabular} & 189 & 0 & 1 & 0 & \begin{tabular}{|l|}
0 \\
\end{tabular} & \begin{tabular}{|l|}
6 \\
\end{tabular} & 6 \\
\hline Cycle 2 & & & & ${ }^{70} \mathrm{Zn}$ & & & & ${ }^{68} \mathrm{Zn}$ & & ${ }^{67} \mathrm{Zn}$ & & & & & $x$ & -64.4 & 183.5 & 0 & 1 & 0 & 0 & 6 & 6 \\
\hline Cycle 3 & & & & & & & & & & ${ }^{70} \mathrm{Zn}$ & & & & ${ }^{68} \mathrm{Zn}$ & $x$ & -57.5 & 171 & 0 & 1 & 0 & 0 & 6 & 6 \\
\hline
\end{tabular}

(b)

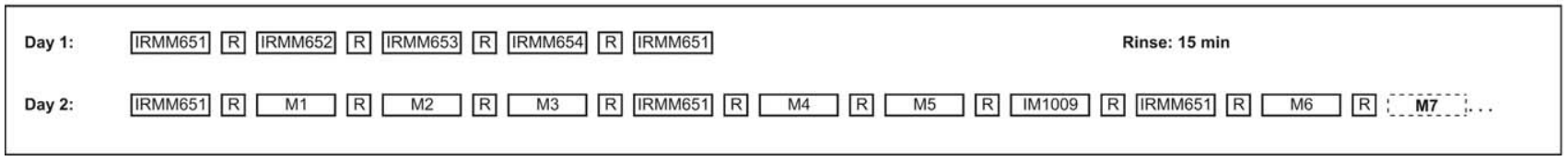

Figure 1. General description of the measurement conditions for all $\mathrm{Zn}$ isotope mixtures, isotopically enriched materials, and natural-like Zn samples. (a) Acquisition methods (including post magnet lens settings). For the natural-like $\mathrm{Zn}$ samples, the isotope mixtures, and IRMM-653, only cycle 1 was applied. For IRMM-652 and IRMM-654, cycles 1, 2, and 3 were applied. F11 was physically moved in front of Ion Counter IC2 for the acquisition of ${ }^{68} \mathrm{Zn}^{+}$signals in cycle 3 . (b) The sequence of measurements over two days. 
Table 3. Nu Plasma operating conditions

\begin{tabular}{|c|c|}
\hline Parameters & Value/Type \\
\hline \multicolumn{2}{|l|}{ Plasma } \\
\hline RF Generator frequency ( $\mathrm{MHz})$ & 27.12 \\
\hline RF power (W) & 1250 \\
\hline Cool gas flow (L $\left.\min ^{-1}\right)$ & 13 \\
\hline Auxiliary gas flow (L $\left.\min ^{-1}\right)$ & 0.8 \\
\hline Sample gas flow $\left(\mathrm{L} \mathrm{min}^{-1}\right)$ & 0.84 \\
\hline \multicolumn{2}{|l|}{ Introduction system } \\
\hline Nebulizer & Seaspray concentric \\
\hline Sample uptake rate $\left(\mu \mathrm{L} \min ^{-1}\right)$ & 400 \\
\hline Spray chamber & Jacketed cinnabar \\
\hline $\begin{array}{l}\text { Sampler/skimmer cones } \\
\text { standard type }\end{array}$ & $\mathrm{Ni} / \mathrm{Ni}$ \\
\hline \multicolumn{2}{|l|}{ Mass spectrometer } \\
\hline Ion energy $(\mathrm{V})$ & 4000 \\
\hline Extraction potential (V) & 2010 \\
\hline Sensitivity $\left(\mathrm{V} / \mu \mathrm{g} \mathrm{g}^{-1}\right)$ & 3 \\
\hline Ion counter dead time (ns) & $7(4)$ \\
\hline \multicolumn{2}{|l|}{ Acquisition } \\
\hline Number of blocks & 3 \\
\hline $\begin{array}{l}\text { Number of measured ratios } \\
\text { per block }\end{array}$ & 10 \\
\hline Integration time $(\mathrm{s})$ & 10 \\
\hline $\begin{array}{l}\text { Magnet settling time (s) (for } \\
\text { dynamic acquisition) }\end{array}$ & 2 \\
\hline
\end{tabular}

the calculation of the average ratios. The standard deviation of the mean (STD/ $\mathrm{n}, n=30$-number of rejections) was taken as the standard uncertainty associated to a ratio result. Raw measurement data can be found in the Supplementary Material section which can be found in the electronic version of this article.

All uncertainties indicated are expanded uncertainties $\mathrm{U}=k \cdot \mathrm{u}_{\mathrm{c}}$ where $\mathrm{u}_{\mathrm{c}}$ is a combined standard uncertainty and $k$ is a coverage factor equal to 2 . Combined standard uncertainties on the certified results were obtained by propagating together individual uncertainty components according to the ISO/GUM guide [32]. In practice, a dedicated software program [33] was used, based on the numerical method of differentiation described by Kragten [34]. It was necessary to apply additive corrections to individual isotope signal intensities to compensate for procedural blank and dead time effects (eqs 11 and 12, Table 1). The uncertainties introduced by these corrections cannot be neglected; however, propagating their uncertainties directly with the repeatability of the measurements could overestimate the resulting combined uncertainty [35]. Additive corrections were therefore translated into unity multiplicative correction factors on ratios (eqs 13 and 3, Table 1) following a method described elsewhere [35].

\section{Results and Discussion}

\section{Evaluation of $K$ Factors by Iteration and Calibration of Natural-Like Zn Samples}

$\mathrm{K}$ factors and measured isotope ratios are reported in Table 4. Equation 3 (Table 1) describes the approach for evaluating the uncertainty of each measured ratio.
For the enriched materials IRMM-652, IRMM-653, and IRMM-654, isotopic abundances were calculated from the measured ratio values (eq 4, Table 1). For the first iteration $(t=0), K$ is set to 1 . Then, atomic weights of the isotopically enriched materials were calculated (eq 5, Table 1). The number of moles of each isotope in the enriched materials could then be obtained (eq 6, Table 1), and the theoretical isotope ratios were calculated (eq 7 , Table 1 ). The mass discrimination factor $K$ was then roughly estimated (eq 8, Table 1), and was reintroduced in eq 4 (Table 1). The iteration continued until the relative difference between two consecutive $K$ values was less than $10^{6}$ (i.e., the residues would induce a bias less than $10^{6}$ relative). Six iterations were necessary because $\mathrm{Zn}$ has a mass discrimination of 2.5 to 3 \% and IRMM-653 is not highly enriched $i^{67} \mathrm{Zn}$ (i.e., four out of five $\mathrm{Zn}$ isotopes over 1\% 1 selative abundance).

For $n\left({ }^{66} \mathrm{Zn}\right) / n\left({ }^{64} \mathrm{Zn}\right)$ and $n\left({ }^{70} \mathrm{Zn}\right) / n\left({ }^{64} \mathrm{Zn}\right), K$ factors were obtained by regression from the linear function existing for each material separately between values and the corresponding average masses. $K$ factor values for $n\left({ }^{68} \mathrm{Zn}\right) / n\left({ }^{64} \mathrm{Zn}\right)$ and $n\left({ }^{67} \mathrm{Zn}\right) / n\left({ }^{64} \mathrm{Zn}\right)$ in the isotopically enriched materials were extrapolated from the linear trends existing for each ratio over the range of values covered with all the mixtures. Three iterations of extrapolation were necessary until stabilization of the regression coefficients. The measured isotope ratios in the enriched materials and isotope mixtures could then be properly corrected for mass discrimination effects.

\section{Mass Discrimination Fluctuations Over Time}

The nebulizerclogged partially during the measurements of mixture M7 on Day 2 and reoptimizingthe nebulizer gas flow-rate to stabilize the signal (from 0.84 to $0.88 \mathrm{~L} \mathrm{~min}^{-1}$ ) changed the mass discrimina tion. The shift was linearly proportional to the mass difference between isotopes for all isotope ratios. The absolute calibration of isotope ratio measurements by means of synthetic mixtures requires that mass discrimination remains stable over time (at least for the period corresponding to the overall measurement session). A noncompensated change in mass discrimination is not compatible with the principle of an iterative calculation of the $K$ factor and the use of this $K$ factor. Thus, the measurement results obtained for M7 and the following mixtures were not taken into account for the calculations presented in this paper.

Furthermore, mass discrimination during MCICPMS measurements can change rapidly between samples and between measurement sessions. Our methods lasted $6 \mathrm{~min}$ (cycle 1 only), and $21 \mathrm{~min}$ (cycles 1 to 3 ), respectively. Long-term fluctuation of the mass discrimination, evaluated from recurring measurements of the same sample (IRMM-651) over two consecutive days, was found to be $0.0041,0.0065$, 


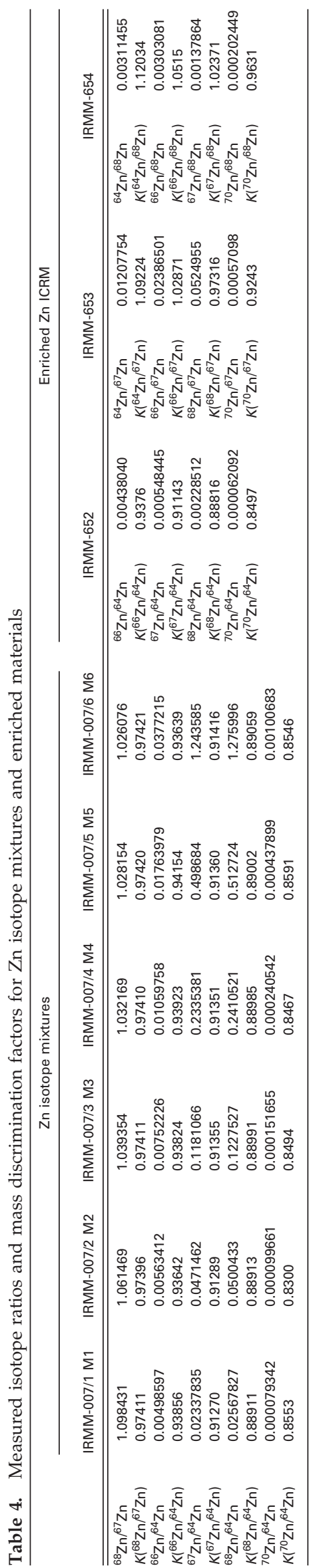

and $0.0082 \%(1 \mathrm{RSD} / \sqrt{ } \mathrm{n}, n=5)$ for $n\left({ }^{68} \mathrm{Zn}\right) / n\left({ }^{67} \mathrm{Zn}\right)$, $n\left({ }^{67} \mathrm{Zn}\right) / n\left({ }^{64} \mathrm{Zn}\right)$, and $n\left({ }^{68} \mathrm{Zn}\right) / n\left({ }^{64} \mathrm{Zn}\right)$, respectively. Since no systematic drift was observed, no correction was made to the data. However, the variability of the mass discrimination was propagated by multiplying the measured isotope ratios by unity factors with relative standard uncertainties equal to the reproducibility values described above. It is noticeable that the average of the measured values for $n\left({ }^{68} \mathrm{Zn}\right) / n\left({ }^{67} \mathrm{Zn}\right)$, $n\left({ }^{67} \mathrm{Zn}\right) / n\left({ }^{64} \mathrm{Zn}\right)$, and $n\left({ }^{68} \mathrm{Zn}\right) / n\left({ }^{64} \mathrm{Zn}\right)$ the first day $(n$ $=2)$ and the second day $(n=3)$ agreed within less than $0.002,0.003$, and $0.005 \%$, respectively, despite the plasma shutdown between the measurements (and no changes of the settings).

The mixing scheme and a first series of iterative calculations were used to determine the $K$ factors for $n\left({ }^{68} \mathrm{Zn}\right) /$ $n\left({ }^{64} \mathrm{Zn}\right), n\left({ }^{67} \mathrm{Zn}\right) / n\left({ }^{64} \mathrm{Zn}\right)$, and $n\left({ }^{68} \mathrm{Zn}\right) / n\left({ }^{67} \mathrm{Zn}\right)$ for each mixture. As the mixtures were measured sequentially in ascending order, the chronological sequence was matching the sequence of ratio values. Figure $2 a, b$, and c display the evolution in time of these $\mathrm{K}$ factors normalized to the corresponding average values (from M1 to M6). The evolution observed for $n\left({ }^{68} \mathrm{Zn}\right) / n\left({ }^{64} \mathrm{Zn}\right), n\left({ }^{67} \mathrm{Zn}\right) / n\left({ }^{64} \mathrm{Zn}\right)$ does not correspond to a time drift of the mass discrimination as for the $n\left({ }^{68} \mathrm{Zn}\right) / n\left({ }^{67} \mathrm{Zn}\right)$ ratio, always close to 1 , the $K$ factor remains constant (Figure 2c). Instead, as explained below, the $K$ factors for the first two series of ratios, ranging each over nearly two orders of magnitude (from $2.10^{-2}$ to 1.1 ), increase steadily as a function of the isotope ratio values.

\section{Change in Mass Discrimination Over the Studied Isotope Ratio Range}

There appears to be more than four times more variability of the $K$ factor within less than $5 \mathrm{~h}$ from varying $n\left({ }^{68} \mathrm{Zn}\right) / n\left({ }^{64} \mathrm{Zn}\right)$ and $n\left({ }^{67} \mathrm{Zn}\right) / n\left({ }^{64} \mathrm{Zn}\right)$ ratio values (respectively 0.0239 and $0.0232 \% \mathrm{RSD} / \sqrt{ } \mathrm{n}, n$ $=6$ mixtures) than that observed over two days from repeated measurements of the same ratios (5 IRMM651 replicates, see above). This variability is linearly proportional to the range of ratios (logarithmic scale) studied, as illustrated in Figure $2 \mathrm{~d}$ and e. This is demonstrating that the hypothesis of constant $K$ factors over the range of isotope ratios covered by the isotopic mixtures and the isotopically enriched materials cannot apply in the case of MC-ICPMS measurements. Thus, the way of getting these $K$ factors and calibrating unknown solutions, originally from iterative calculations alone (as is the case with TIMS measurements), must be adapted.

\section{Extrapolating Mass Discrimination for $n\left({ }^{66} \mathrm{Zn}\right) /$ $n\left({ }^{64} \mathrm{Zn}\right)$ and the $n\left({ }^{70} \mathrm{Zn}\right) / n\left({ }^{64} \mathrm{Zn}\right)$ Extreme Values from Other Isotope Ratios in Same Sample}

Absolute calibration by means of synthetic isotopic mixtures necessitates the determination of all possi- 


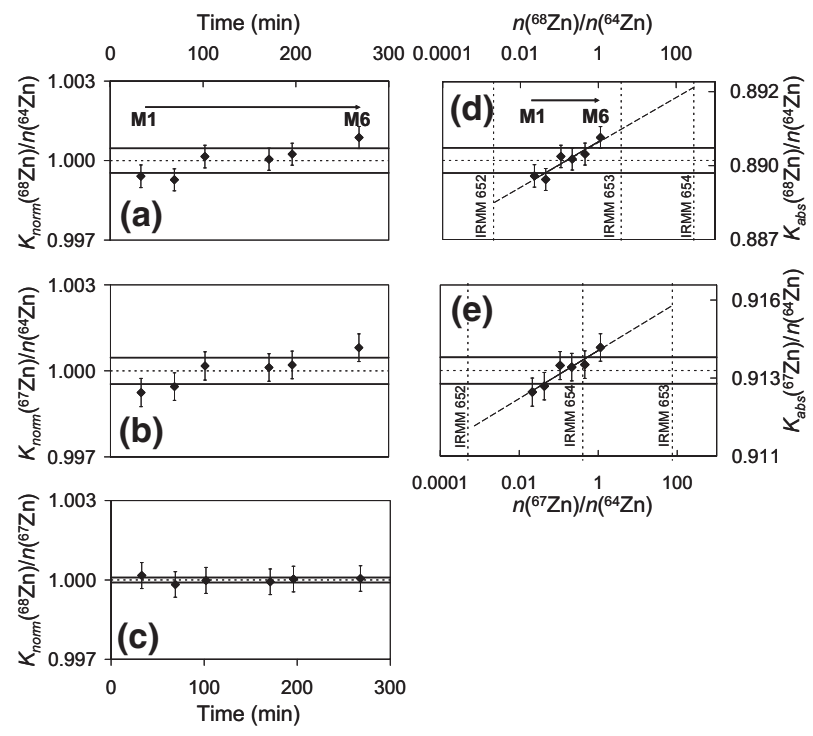

Figure 2. (a), (b), and (c): Normalized (to average) $K$ factors for $n\left({ }^{68} \mathrm{Zn}\right) / n\left({ }^{64} \mathrm{Zn}\right), n\left({ }^{67} \mathrm{Zn}\right) / n\left({ }^{64} \mathrm{Zn}\right)$, and $n\left({ }^{68} \mathrm{Zn}\right) / n\left({ }^{67} \mathrm{Zn}\right)$, respectively, as a function of time for isotope mixtures M1 to M6. The vertical bars are the expanded $(k=2)$ uncertainties of the individual $K$ factors, dotted lines represent the mean of the six $K$ factors within expanded $(k=2)$ uncertainty (solid lines). (d) and (e): Absolute $K$ factors for $n\left({ }^{68} \mathrm{Zn}\right) / n\left({ }^{64} \mathrm{Zn}\right)$ and $n\left({ }^{67} \mathrm{Zn}\right) / n\left({ }^{64} \mathrm{Zn}\right)$, respectively, as a function of isotope ratio values for isotope mixtures M1 to M6. The vertical bars (solid lines) are the expanded $(k=2)$ uncertainties of the individual $\mathrm{K}$ factors. Horizontally, dotted lines represent the mean of the $6 \mathrm{~K}$ factors within expanded $(k=2)$ uncertainty (solid lines). $\mathrm{K}$ factor values for the same ratios in the three isotopically enriched materials (IRMM-652, IRMM-653 and IRMM-654) are extrapolated from the linear regressions plotted through the values obtained with the isotope mixtures.

ble ratios. For low abundance isotopes it may be necessary to use ion counting detectors and thus lengthy multiple cycle acquisition methods. This was done for only two of the isotopically enriched materials (not needed for IRMM-653). For all the other samples only the 1 cycle method of acquisition was involved to prevent unnecessary degradation of the measurement repeatability (resulting from the extension of the time separating successive repeats in the case of the acquisition method with 3 cycles). Under these conditions however and, as expected, the uncertainty associated with the determination of $K$ factors for the ratios involving the lowest abundance isotopes was degraded due to insufficient counting rates. The practice with TIMS measurements is to apply to these ratios the average of the $K$ factor values obtained with the major ratios. With our MC-ICPMS measurements we developed an alternative way.

Quétel et al. [36] showed that the normalized mass discrimination factor $\varepsilon$ was strongly correlated with the average atomic mass of the two isotopes involved in its calculation (eq 14, Table 1). This suggests that applying the same $\varepsilon$ to correct for mass discrimination all isotope ratios measured simultaneously generates a bias. It was later confirmed by Vance and
Thirwall [37]. For our $\mathrm{Zn}$ data, $\varepsilon$ also appears to be linearly correlated with the isotope pair mass average (Figure 3 ). The normalized $\varepsilon$ factor can thus be written as a first-order function of the average atomic mass (eqs 14 to 19, Table 1).

During the iterative calculations, we calculated the successive $\varepsilon$ values for the $n\left({ }^{66} \mathrm{Zn}\right) / n\left({ }^{64} \mathrm{Zn}\right)$ and the $n\left({ }^{70} \mathrm{Zn}\right) / n\left({ }^{64} \mathrm{Zn}\right)$ ratios from the results on $n\left({ }^{68} \mathrm{Zn}\right) /$ $n\left({ }^{64} \mathrm{Zn}\right), n\left({ }^{67} \mathrm{Zn}\right) / n\left({ }^{64} \mathrm{Zn}\right)$, and $n\left({ }^{68} \mathrm{Zn}\right) / n\left({ }^{67} \mathrm{Zn}\right)$ ratios.

These results suggest, providing that two certified isotope ratios (involving major abundance isotopes) are available for a given material, a way to calculate the $\varepsilon$ associated to any other pair of isotopes. They also suggest a revision of eq 2 (Table 1 ) into the form described by eq 19 (Table 1), with $a$ and $b$ obtained from the linear regression. This equation requires, however, further validation from investigations with other elements, which will be reported in a separate publication.

\section{Extrapolating Mass Discrimination for $n\left({ }^{68} \mathrm{Zn}\right) /$ $n\left({ }^{64} \mathrm{Zn}\right)$ and the $n\left({ }^{67} \mathrm{Zn}\right) / n\left({ }^{64} \mathrm{Zn}\right)$ Extreme Values from Same Isotope Ratios in Other Samples}

Upon completion of the first series of iterations, the trends illustrated in Figure $2 \mathrm{~d}$ and e were used to extrapolate $K$ factors for $n\left({ }^{68} \mathrm{Zn}\right) / n\left({ }^{64} \mathrm{Zn}\right)$ and $n\left({ }^{67} \mathrm{Zn}\right) / n\left({ }^{64} \mathrm{Zn}\right)$ in the isotopically enriched materials specifically (eqs 20 and 21). A second round of iterations was then performed to produce a new series of $K$ factor values for $n\left({ }^{68} \mathrm{Zn}\right) / n\left({ }^{64} \mathrm{Zn}\right)$ and $n\left({ }^{67} \mathrm{Zn}\right) / n\left({ }^{64} \mathrm{Zn}\right)$ in the isotopic mixtures that, in turn, provided further refined $K$ factors for the ratio values of the isotopically enriched materials. This was repeated for a total of three iterations where it was found that the last significant digit in the isotope ratios in the mixtures did not change. This combination of iterations shifted the values of the $n\left({ }^{68} \mathrm{Zn}\right) /$ $n\left({ }^{67} \mathrm{Zn}\right), n\left({ }^{67} \mathrm{Zn}\right) / n\left({ }^{64} \mathrm{Zn}\right)$, and $n\left({ }^{68} \mathrm{Zn}\right) / n\left({ }^{64} \mathrm{Zn}\right)$ ratios for the isotopic mixtures M1 to M6 by $0.01-0.02 \%$, $0.001 \%$, and $0.002-0.013 \%$, respectively. Standard uncertainties on slope and intercept of the linear regres-

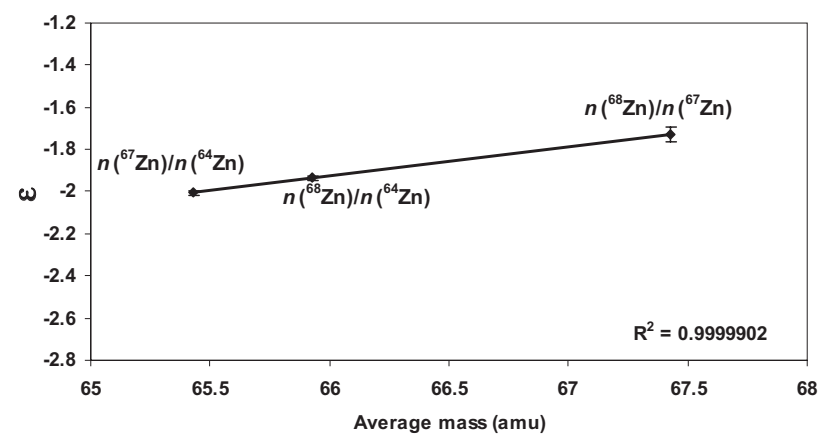

Figure 3. Variation of $\varepsilon$ (normalized mass discrimination factor according to the exponential model) against average atomic mass for the isotopic mixture M2. $\varepsilon$ is calculated for each isotope pair independently of the others. 
Table 5. Comparison of MC-ICPMS and TIMS based strategies for the absolute calibration of isotope ratio measurements by means of gravimetric synthetic isotopic mixtures. IEM stands for isotopically enriched materials, IM for isotope mixtures and MD for mass discrimination

\begin{tabular}{|c|c|c|}
\hline & MC-ICPMS & TIMS \\
\hline 1 Purification of IEM & Yes & Yes \\
\hline $\begin{array}{l}2 \text { Determination of the purity } \\
\text { and stoichiometry of IEM }\end{array}$ & Yes & Yes \\
\hline $\begin{array}{l}3 \text { Production of IM by low uncertainty } \\
\text { substitution weighing }\end{array}$ & Yes & Yes \\
\hline 4 Isotope ratio mass spectrometry & Yes & Yes \\
\hline
\end{tabular}

measurements in IEM and IM

5 Temporal fluctuation of mass discrimination

$6 K$ factor calculations: first iteration stage

\section{$7 \mathrm{~K}$ factor calculations:} second iteration stage

8 Calibration of isotope ratio measured in following unknown materials
Evaluated through recurrent measurements of the same sample

Multiplication of isotope ratio results with unity factors carrying as standard uncertainty the variability of the mass discrimination

MD model: exponential law

$\varepsilon$ is specific to each isotope ratio measured (linearly proportional to average mass)

$6.1 \varepsilon$ for $n\left({ }^{66} \mathrm{Zn}\right) / n\left({ }^{64} \mathrm{Zn}\right)$ and $n\left({ }^{70} \mathrm{Zn}\right) / n\left({ }^{64} \mathrm{Zn}\right)$ in IM and IEM extrapolated from other isotope ratios in same samples

6.2 End of first iteration stage when linear regression coefficients are constant $(6$ rounds)

$K$ factor values are linearly proportional (following an upward trend) to logarithm of ratio values over the range covered by all IM

$7.1 K$ factor values for $n\left({ }^{68} \mathrm{Zn}\right) / n\left({ }^{64} \mathrm{Zn}\right)$ and $n\left({ }^{67} \mathrm{Zn}\right) / n\left({ }^{64} \mathrm{Zn}\right)$ in IEM extrapolated from same isotope ratios in all IM samples

$7.2 \varepsilon$ for $n\left({ }^{66} \mathrm{Zn}\right) / n\left({ }^{64} \mathrm{Zn}\right)$ and $n\left({ }^{70} \mathrm{Zn}\right) / n\left({ }^{64} \mathrm{Zn}\right)$ in IEM extrapolated from other isotope ratios in same samples

7.3 corrected isotope ratios calculated in all IEM

7.4 corrected isotope ratios calculated in all IM using weighing results

$7.5 \mathrm{~K}$ factor values for all isotope ratios in IM re-calculated

7.6 End of second iteration stage when linear regression coefficients are constant (3 rounds)

External, from "standard-sample-standard" bracketing using appropriate IM as standard

\section{Not considered}

MD model: exponential law

$\varepsilon$ is not specific to each isotope ratio measured

all $\varepsilon$ values are averaged together

Not considered

From calculations, using the pre-determined average $K$ value sions, calculated according to reference [38], were propagated into the combined uncertainty estimations.

\section{Adaptation to MC-ICPMS Measurements of the Strategy for Absolute Calibration by Means of Gravimetric Isotopic Mixtures}

Table 5 compares strategies deployed for MC-ICPMS and TIMS measurements. There are mostly four fundamental differences (steps 5 to 8). First, fluctuations of the mass discrimination effects across the measurement sequence are taken into account for the uncertainty estimation in the case of MC-ICPMS measure- ments. Second, mass discrimination appears to be linearly correlated during each individual measurement with the average mass of the isotope ratios. This property is used to evaluate $K$ factors for the ratios involving the low abundance isotopes. Third, at the end of the first cycle of iterations, as the $K$ factors for $n\left({ }^{67} \mathrm{Zn}\right) / n\left({ }^{64} \mathrm{Zn}\right)$ and $n\left({ }^{68} \mathrm{Zn}\right) / n\left({ }^{64} \mathrm{Zn}\right)$ over the six mixtures studied appear to be linearly proportional to the logarithm of the isotope ratio values following an upward trend, the $K$ factors in the isotopically enriched materials are extrapolated from the regression figures and additional rounds of iterations are introduced to further smooth out the entire set of $K$ factor values. Fourth, the way these results are eventually 
Table 6. Absolute isotope ratio values for the candidate isotopic certified reference3 materials (ICRMs) involved in this study. All uncertainties indicated are expanded uncertaintly $\mathrm{U}=k \cdot \mathrm{u}_{\mathrm{c}}$ where $\mathrm{u}_{\mathrm{c}}$ is the combined standard uncertainty. They are given in parentheses and include a coverage factor $k=2$. They apply to the last two digits of the value.

\section{$\mathrm{Zn}$ isotope mixtures}

\begin{tabular}{|c|c|c|c|c|c|c|}
\hline & $\begin{array}{c}\text { IRMM-007/1 } \\
\text { M1 }\end{array}$ & $\begin{array}{c}\text { IRMM-007/2 } \\
\text { M2 }\end{array}$ & $\begin{array}{l}\text { IRMM-007/3 } \\
\text { M3 }\end{array}$ & $\begin{array}{c}\text { IRMM-007/4 } \\
\text { M4 }\end{array}$ & $\begin{array}{l}\text { IRMM-007/5 } \\
\text { M5 }\end{array}$ & $\begin{array}{c}\text { IRMM-007/6 } \\
\text { M6 }\end{array}$ \\
\hline \multicolumn{7}{|c|}{ Isotope amount ratios } \\
\hline$n\left({ }^{68} \mathrm{Zn}\right) / n\left({ }^{67} \mathrm{Zn}\right)$ & $1.07000(47)$ & $1.03383(45)$ & $1.01245(45)$ & $1.00544(45)$ & $1.00162(45)$ & $0.99961(45)$ \\
\hline$n\left({ }^{66} \mathrm{Zn}\right) / n\left({ }^{64} \mathrm{Zn}\right)$ & $0.0046797(58)$ & $0.0052758(57)$ & $0.0070574(57)$ & $0.0099540(60)$ & $0.0166088(80)$ & $0.035323(17)$ \\
\hline$n\left({ }^{67} \mathrm{Zn}\right) / n\left({ }^{64} \mathrm{Zn}\right)$ & $0.0213374(98)$ & $0.043039(20)$ & $0.107896(50)$ & $0.213339(99)$ & $0.45560(21)$ & $1.13683(52)$ \\
\hline$n\left({ }^{68} \mathrm{Zn}\right) / n\left({ }^{64} \mathrm{Zn}\right)$ & $0.0228309(89)$ & $0.044495(18)$ & $0.109239(45)$ & $0.214499(88)$ & $0.45634(19)$ & $1.13639(46)$ \\
\hline$n\left({ }^{70} \mathrm{Zn}\right) / n\left({ }^{64} \mathrm{Zn}\right)$ & $0.00006757(32)$ & $0.00008300(31)$ & $0.00012911(32)$ & $0.00020407(44)$ & $0.00037629(90)$ & $0.0008606(23)$ \\
\hline \multicolumn{7}{|c|}{ Amount fraction (\%) } \\
\hline$n\left({ }^{64} \mathrm{Zn}\right) / n(\mathrm{Zn})$ & 95.3366 (16) & $91.5002(28)$ & $81.6779(56)$ & $69.5412(79)$ & $51.8425(94)$ & 30.2169 (79) \\
\hline$n\left({ }^{66} \mathrm{Zn}\right) / n(\mathrm{Zn})$ & $0.44614(55)$ & $0.48274(52)$ & $0.57644(45)$ & $0.69221(39)$ & $0.86104(34)$ & $1.06734(38)$ \\
\hline$n\left({ }^{67} \mathrm{Zn}\right) / n(\mathrm{Zn})$ & $2.03423(90)$ & $3.9381(17)$ & $8.8127(36)$ & $14.8359(55)$ & $23.6193(75)$ & $34.3516(90)$ \\
\hline$n\left({ }^{68} \mathrm{Zn}\right) / n(\mathrm{Zn})$ & $2.17662(82)$ & $4.0713(15)$ & $8.9224(31)$ & 14.9165 (48) & $23.6576(66)$ & 34.3382 (82) \\
\hline$n\left({ }^{70} \mathrm{Zn}\right) / n(\mathrm{Zn})$ & $0.006442(31)$ & $0.007594(29)$ & $0.010545(26)$ & $0.014191(31)$ & $0.019508(46)$ & $0.026004(70)$ \\
\hline \multicolumn{7}{|c|}{ Molar mass (g mol $\left.\mathrm{mol}^{-1}\right)$} \\
\hline & $64.086398(52)$ & $64.219983(96)$ & $64.56201(19)$ & $64.98462(27)$ & $65.60090(32)$ & $66.35393(27)$ \\
\hline
\end{tabular}




\begin{tabular}{|c|c|c|c|c|c|c|c|c|c|}
\hline \multicolumn{7}{|c|}{ Enriched Zn ICRM } & \multicolumn{3}{|c|}{ Natural-like Zn ICRM } \\
\hline & IRMM-652 & & IRMM-653 & & IRMM-654 & & IRMM-651 & IM-1009 & IRMM-3702 ${ }^{\mathrm{a}}$ \\
\hline \multicolumn{10}{|c|}{ Isotope amount ratios } \\
\hline$n\left({ }^{6} \mathrm{Zn}\right) / n\left({ }^{64} \mathrm{Zn}\right)$ & $0.0041073(59)$ & $n\left({ }^{64} \mathrm{Zn}\right) / n\left({ }^{67} \mathrm{Zn}\right)$ & $0.0131915(81)$ & $n\left({ }^{64} \mathrm{Zn}\right) / n\left({ }^{68} \mathrm{Zn}\right)$ & $0.0034894(38)$ & $n\left({ }^{66} \mathrm{Zn}\right) / n\left({ }^{64} \mathrm{Zn}\right)$ & $0.55717(30)$ & $0.56373(30)$ & $0.56397(30)$ \\
\hline$n\left({ }^{67} \mathrm{Zn}\right) / n\left({ }^{64} \mathrm{Zn}\right)$ & $0.00049987(96)$ & $n\left({ }^{66} \mathrm{Zn}\right) / n\left({ }^{67} \mathrm{Zn}\right)$ & $0.0245516(70)$ & $n\left({ }^{66} \mathrm{Zn}\right) / n\left({ }^{68} \mathrm{Zn}\right)$ & $0.0031868(46)$ & $n\left({ }^{67} \mathrm{Zn}\right) / n\left({ }^{64} \mathrm{Zn}\right)$ & $0.080702(34)$ & $0.082121(36)$ & $0.082166(35)$ \\
\hline$n\left({ }^{68} \mathrm{Zn}\right) / n\left({ }^{64} \mathrm{Zn}\right)$ & $0.0020295(23)$ & $n\left({ }^{68} \mathrm{Zn}\right) / n\left({ }^{67} \mathrm{Zn}\right)$ & $0.051086(36)$ & $n\left({ }^{67} \mathrm{Zn}\right) / n\left({ }^{68} \mathrm{Zn}\right)$ & $0.0014113(17)$ & $n\left({ }^{68} \mathrm{Zn}\right) / n\left({ }^{64} \mathrm{Zn}\right)$ & $0.36627(12)$ & $0.37485(14)$ & $0.37519(16)$ \\
\hline$n\left({ }^{70} \mathrm{Zn}\right) / n\left({ }^{64} \mathrm{Zn}\right)$ & $0.00005276(34)$ & $n\left({ }^{70} \mathrm{Zn}\right) / n\left({ }^{67} \mathrm{Zn}\right)$ & $0.0005278(18)$ & $n\left({ }^{70} \mathrm{Zn}\right) / n\left({ }^{68} \mathrm{Zn}\right)$ & $0.00019498(78)$ & $n\left({ }^{70} \mathrm{Zn}\right) / n\left({ }^{64} \mathrm{Zn}\right)$ & $0.011981(22)$ & $0.012399(23)$ & $0.012418(23)$ \\
\hline \multicolumn{10}{|c|}{ Amount fraction (\%) } \\
\hline$n\left({ }^{64} \mathrm{Zn}\right) / n(\mathrm{Zn})$ & $99.33550(59)$ & & $1.21095(71)$ & & $0.34607(37)$ & & $49.6002(84)$ & $49.1858(90)$ & $49.1704(83)$ \\
\hline$n\left({ }^{66} \mathrm{Zn}\right) / n(\mathrm{Zn})$ & $0.40800(58)$ & & $2.25377(72)$ & & $0.31606(45)$ & & $27.636(11)$ & $27.728(11)$ & $27.731(11)$ \\
\hline$n\left({ }^{67} \mathrm{Zn}\right) / n(\mathrm{Zn})$ & $0.049655(95)$ & & $91.7972(32)$ & & $0.13997(17)$ & & $4.0028(10)$ & $4.0392(11)$ & $4.0401(18)$ \\
\hline$n\left({ }^{68} \mathrm{Zn}\right) / n(\mathrm{Zn})$ & $0.20161(23)$ & & $4.6896(31)$ & & $99.17856(83)$ & & $18.1670(58)$ & $18.4375(59)$ & $18.4483(69)$ \\
\hline$n\left(^{70} \mathrm{Zn}\right) / n(\mathrm{Zn})$ & $0.005241(34)$ & & $0.04845(17)$ & & $0.019338(77)$ & & $0.5943(12)$ & $0.6099(12)$ & $0.6106(11)$ \\
\hline \multicolumn{10}{|c|}{ Molar mass ( $\left.\mathrm{g} \mathrm{mol}^{-1}\right)$} \\
\hline & $63.947152(14)$ & & $66.916506(30)$ & & $67.903692(25)$ & & $65.36254(21)$ & $65.37721(22)$ & $65.37777(22)$ \\
\hline
\end{tabular}

a IRMM-3702 was calibrated against IRMM-651. 
used to calibrate the measurements performed on unknown materials is different. In this study, the isotopic composition of three different natural-like $\mathrm{Zn}$ materials was obtained by external bracketing using various combinations of isotopic mixture materials to calibrate the measurements. IRMM-651 values were obtained by averaging the corrected isotope ratios obtained from bracketing by M3 and M4, and M5 and M6 (eq 22, Table 1). IM-1009 was calibrated externally using M5 and M6 (eq 23, Table 1). IRMM3702 values were obtained by averaging three measurement results calibrated with IRMM-651 (eq 24, Table 1).

The final results obtained for the isotopic mixtures, the isotopically enriched materials, and the various natural-like $\mathrm{Zn}$ materials investigated are compiled in Table 6.

\section{Method Validation}

While uncertainty estimation is in itself a way to validate an experimental protocol, the ISO guide "General requirements for the competence of testing and calibration laboratories", ISO/IEC17025, chapter 5.4.5, [39] also includes a systematic assessment of factors influencing the result and a comparison of results between methods as approaches by which validation may be achieved. These steps were undertaken in the present study, and are presented here.

\section{Uncertainty Distribution}

The relative expanded uncertainty $(k=2)$ estimated for $n\left({ }^{68} \mathrm{Zn}\right) / n\left({ }^{67} \mathrm{Zn}\right)$ was $\sim 0.044 \%$ in all synthetic isotopic mixtures consistently. For $n\left({ }^{68} \mathrm{Zn}\right) / n\left({ }^{64} \mathrm{Zn}\right)$ and $n\left({ }^{67} \mathrm{Zn}\right) /$ $n\left({ }^{64} \mathrm{Zn}\right)$ it ranged from $\sim 0.040$ to $0.048 \%$ in the synthetic isotopic mixtures and from $\sim 0.030$ to $0.19 \%$ in the isotopically enriched materials. The uncertainty on the weighing (mostly r.s.u. $=0.01 \%, k=1$ ) was the major contributor to the total budget by far ( $\sim 90 \%)$, followed by the uncertainty on the correction for the impurity content in the enriched materials and the variability of mass discrimination in time. It should be noted that the major contribution to the uncertainty on the weighing of the zinc pieces came from the reproducibility of the balance.

Repeatability on major isotope ratios measurements accounted for $<1 \%$. This suggests that smaller final combined uncertainty can only be obtained from improvements on the relative standard uncertainty associated with weighing.

The relative expanded uncertainty $(k=2)$ estimated for all ratios in the three natural-like zinc materials ranged over $\sim 0.034$ to $0.054 \%$ (and $\sim 0.034$ to $0.044 \%$ for $n\left({ }^{68} \mathrm{Zn}\right.$ )/ $n\left({ }^{64} \mathrm{Zn}\right)$ and $n\left({ }^{67} \mathrm{Zn}\right) / n\left({ }^{64} \mathrm{Zn}\right)$, specifically). These estimates were mostly due $(98 \%)$ to the uncertainty associated with the ratios of the isotopic mixtures used as ICRMs for calibration purposes. In this case also the repeatability of measurements accounted for $\sim 2 \%$ of the uncertainty budget. The relative contribution of the different uncertainty sources for IRMM-651 is shown in Table 7.

However, it must be noted that significant differences were observed depending on whether or not the uncertainties associated to the ICRMs involved in the calibration schemes were treated as fully independent quantities (which they were not). When four different mixtures were used for the calibration, the combined uncertainties estimated were up to a factor $\sim 2$ higher when the correlations from common weighing and isotope ratio measurements in the isotopically enriched materials were considered. This example shows how failing to account for the correlations existing between different materials involved in the same measurement scheme might lead to major underestimations of the final combined uncertainties. In contrast, involving $n$ ICRMs of a similar nature (i.e., with uncertainties of nearly identical magnitude) but completely independent (i.e., not being prepared and/or calibrated under the same conditions and with the same reference materials) reduces the influence of the uncertainty of these ICRMs values by $\sqrt{ } \mathrm{n}$. If independent ICRMs of the same element are available, this property of uncertainty propagation can be exploited to improve uncertainty budgets.

\section{Comparison of Results Between Methods}

The results obtained at IRMM using MC-ICPMS were compared with results obtained at IRMM by TIMS for all the mixtures and IRMM-651, and at LGC (UK) by MC-ICPMS for IRMM-651. These comparisons are illustrated for $n\left({ }^{68} \mathrm{Zn}\right) / n\left({ }^{64} \mathrm{Zn}\right), n\left({ }^{67} \mathrm{Zn}\right) / n\left({ }^{64} \mathrm{Zn}\right)$, and $n\left({ }^{68} \mathrm{Zn}\right) / n\left({ }^{67} \mathrm{Zn}\right)$ for mixtures $\mathrm{M} 3$ to $\mathrm{M} 6$ in Figure $4 \mathrm{a}-\mathrm{f}$.

These figures show excellent agreement within stated uncertainties between the three sets of results. The uncertainties associated to the TIMS results are consistently larger than those obtained by MCICPMS. This is, at least partially, because the TIMS had only one detector. The same reason may explain the 3 to 171 times lower isotope ratio repeatability for the MC-ICPMS than for the TIMS results. Figure $4 \mathrm{~d}-\mathrm{f}$ confirm the similarity in performance achieved between the two MC-ICPMS. Different methods of calibrating the IRMM-651 ratios are also illustrated: external "standard-sample-standard" bracketing (using M3-M3, M3-M4, and M5-M6 for the Nu Plasma; M4-M4 for the Neptune) and application of an average correction factor (from M1 to M9 results, for the TIMS). The results show that irrespective of the methods used, consistent results for the $n\left({ }^{68} \mathrm{Zn}\right) /$ $n\left({ }^{64} \mathrm{Zn}\right), n\left({ }^{67} \mathrm{Zn}\right) / n\left({ }^{64} \mathrm{Zn}\right)$, and $n\left({ }^{68} \mathrm{Zn}\right) / n\left({ }^{67} \mathrm{Zn}\right)$ ratios were obtained.

The results of this comparison also demonstrate that mixtures IRMM-007 /3 to /6 can be used for 
Table 7. Relative contribution (\%) of the different sources of uncertainty for IRMM-651 isotope ratios. Steps 1 to 3 refer to the weighing sequence described in Table 2

\begin{tabular}{|c|c|c|c|c|}
\hline & $n\left({ }^{66} \mathrm{Zn}\right) / n\left({ }^{64} \mathrm{Zn}\right)$ & $n\left({ }^{67} \mathrm{Zn}\right) / n\left({ }^{64} \mathrm{Zn}\right)$ & $n\left({ }^{68} \mathrm{Zn}\right) / n\left({ }^{64} \mathrm{Zn}\right)$ & $n\left({ }^{70} \mathrm{Zn}\right) / n\left({ }^{64} \mathrm{Zn}\right)$ \\
\hline s.u. on the metrological weighing & 92.1 & 84.4 & 84.1 & 93.8 \\
\hline Step 1 & 75.3 & 71.1 & 40.5 & 59.5 \\
\hline Step 2 & 12 & 2.3 & 27.6 & 34.3 \\
\hline Step 3 & 4.8 & 11 & 16 & 0 \\
\hline s.u. on the correction for impurity & 5.2 & 5.9 & 8.5 & 5 \\
\hline s.u. on the mass discrimination variability in time & 2.4 & 9.3 & 5.8 & 0.6 \\
\hline s.u. on the isotope ratio repeatability & 0.3 & 0.4 & 1.6 & 0.6 \\
\hline s.u. on the correction for procedural blank & $<0.1$ & $<0.1$ & $<0.1$ & $<0.1$ \\
\hline s.u. on the correction for ion counter dead time effect & $<0.1$ & $<0.1$ & $<0.1$ & $<0.1$ \\
\hline s.u. on nuclidic mass & $<0.1$ & $<0.1$ & $<0.1$ & $<0.1$ \\
\hline s.u. on the correction for stoichiometry & 0 & 0 & 0 & 0 \\
\hline
\end{tabular}

s.u.: standard uncertainty.

the calibration of natural-like $\mathrm{Zn}$ samples by MCICPMS.

\section{Natural Zn Isotopic Data in Literature}

Isotopic composition of natural $\mathrm{Zn}$ has been studied a number of times in the last 60 years to establish the atomic weight of this element. The currently accepted

Isotope mixtures

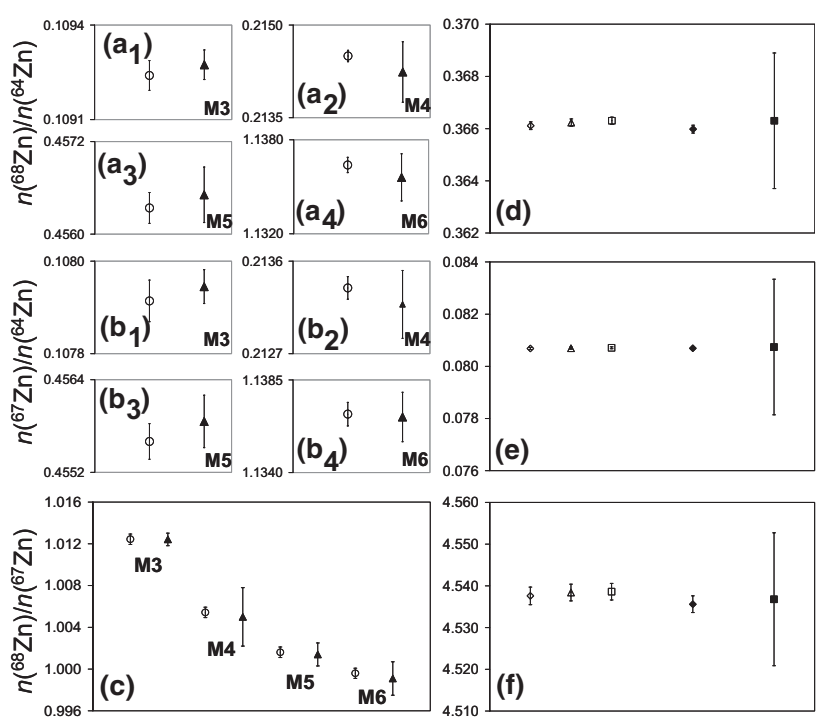

Figure 4. $\left(\mathbf{a}_{1}\right)$ to $\left(\mathbf{a}_{4}\right),\left(\mathbf{b}_{1}\right)$ to $\left(\mathbf{b}_{4}\right)$, and (c): Comparison of absolute values for $n\left({ }^{68} \mathrm{Zn}\right) / n\left({ }^{64} \mathrm{Zn}\right), n\left({ }^{67} \mathrm{Zn}\right) / n\left({ }^{64} \mathrm{Zn}\right)$, and $n\left({ }^{68} \mathrm{Zn}\right) / n\left({ }^{67} \mathrm{Zn}\right)$, respectively, in isotopic mixtures M3 to M6. Results designated by an open circle are obtained by MC-ICPMS (Nu Plasma) and by a filled triangle are obtained by TIMS. (d), (e), and (f): Comparison of absolute values for $n\left({ }^{68} \mathrm{Zn}\right) / n\left({ }^{64} \mathrm{Zn}\right), n\left({ }^{67} \mathrm{Zn}\right) / n\left({ }^{64} \mathrm{Zn}\right)$, and $n\left({ }^{68} \mathrm{Zn}\right) / n\left({ }^{67} \mathrm{Zn}\right)$ in IRMM-651. Empty markers are results obtained with the Nu Plasma calibrated by double bracketing with M3 and M3, M3 and M4, M5 and M6, (open diamond, open triangle, and open square, respectively). Results corresponding to filled diamond are calibrated by double bracketing with M4 and M4 obtained by MC-ICPMS (Neptune). Results designated by a filled square are calibrated by an average of M1 to M9 obtained by TIMS. For all figures, the vertical bars are the expanded uncertainty $(k=2)$ of the individual values (possibly smaller than the symbols). value [5] of the atomic weight of zinc was produced by Chang et al. [1]. We had the opportunity to measure the $\mathrm{Zn}$ isotope ratios in one of the materials (Sample 2, renamed IM-1009 for this study) used by

\section{IM 1009}

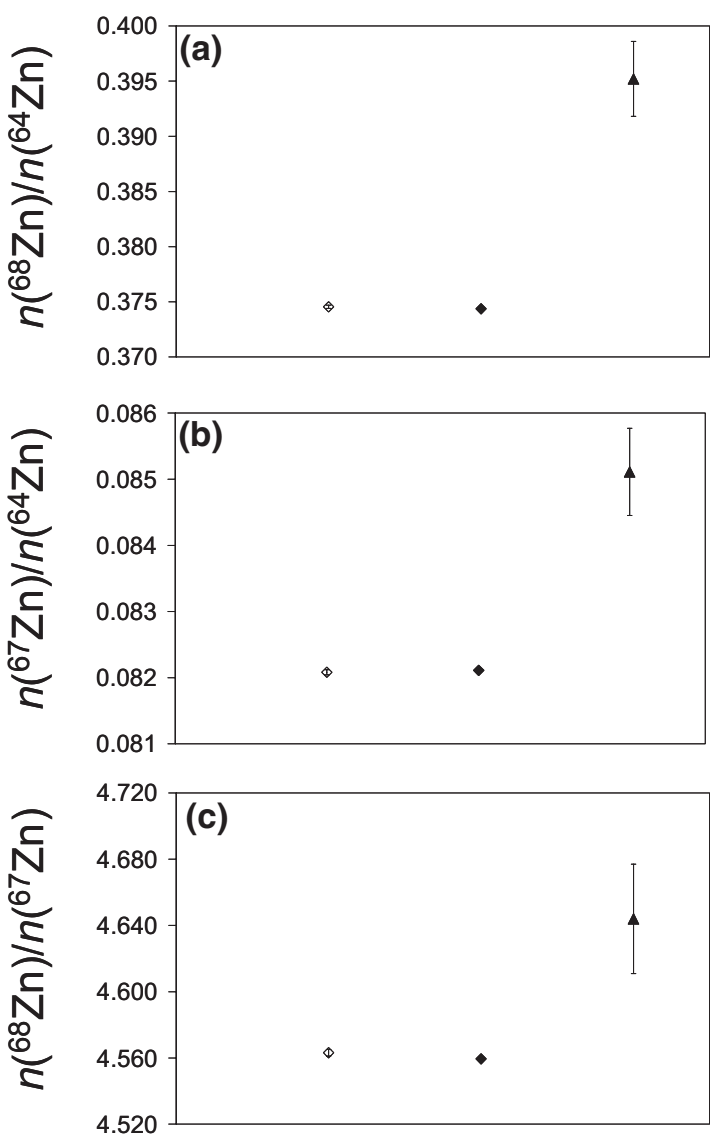

Figure 5. (a), (b), and (c): Absolute values for $n\left({ }^{68} \mathrm{Zn}\right) / n\left({ }^{64} \mathrm{Zn}\right)$, $n\left({ }^{67} \mathrm{Zn}\right) / n\left({ }^{64} \mathrm{Zn}\right)$, and $n\left({ }^{68} \mathrm{Zn}\right) / n\left({ }^{67} \mathrm{Zn}\right)$ in IM-1009. Results designated by an open diamond and filled diamond are obtained for this study with the two MC-ICPMS (Nu Plasma and Neptune); filled triangle represents results as reported in reference 1 for the same material ("Sample 2"). 


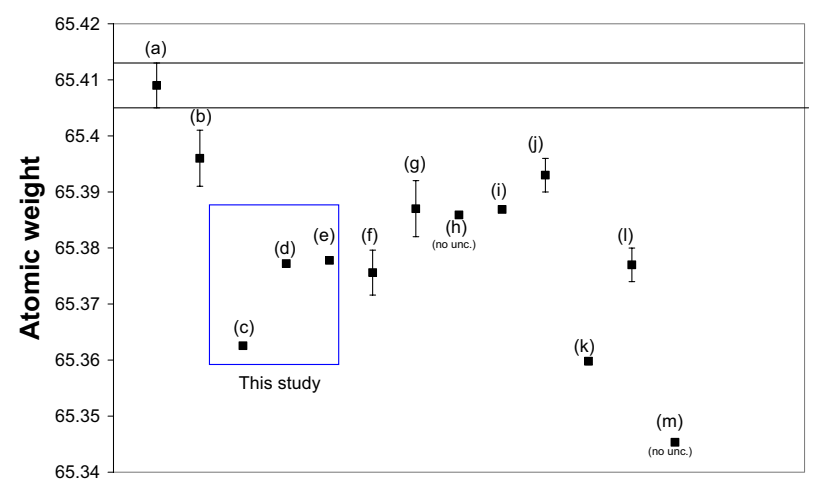

Figure 6. Atomic weight of $\mathrm{Zn}$ as reported in literature. (a) Chang et al. [1] and (IUPAC [8]; (b) Rosman [6]; (c) IRMM-651; (d) IM-1009; (e) IRMM-3702; (f) Tanimizu et al. [9]; (g) Leyland et al. [41]; (h) Hess et al. [40]; (i) Bainbridge et al. [42]; (j) Hibbs [43]; (k) Okamoto et al. [44]; (1) Marinenko et al. [7]; (m) Konishi et al. [45]. (c), (d), and (e) are from the present study.

Chang et al. [1] for their determination of the $\mathrm{Zn}$ atomic weight.

The $n\left({ }^{68} \mathrm{Zn}\right) / n\left({ }^{67} \mathrm{Zn}\right), \quad n\left({ }^{68} \mathrm{Zn}\right) / n\left({ }^{64} \mathrm{Zn}\right), \quad$ and $n\left({ }^{67} \mathrm{Zn}\right) / n\left({ }^{64} \mathrm{Zn}\right)$ values reported in Figure $5 \mathrm{a}-\mathrm{c}$ from reference [1] were calculated from isotope ratios available in this publication. These values are not in accordance with those obtained here using either MC-ICPMS instruments. The relative difference between these results and ours is significant [1.35 (27)\% per atomic mass unit], and clearly vary linearly as a function of the mass difference between isotopes: 1.73 $(72) \%$ for $n\left({ }^{68} \mathrm{Zn}\right) / n\left({ }^{67} \mathrm{Zn}\right), 2.96(67) \%$ for $n\left({ }^{66} \mathrm{Zn}\right) /$ $n\left({ }^{64} \mathrm{Zn}\right), 3.64(81) \%$ for $n\left({ }^{67} \mathrm{Zn}\right) / n\left({ }^{64} \mathrm{Zn}\right), 5.43(91) \%$ for $n\left({ }^{68} \mathrm{Zn}\right) / n\left({ }^{64} \mathrm{Zn}\right)$, and $5.6(4.2) \%$ for $n\left({ }^{70} \mathrm{Zn}\right) / n\left({ }^{64} \mathrm{Zn}\right)$. This strongly suggests a systematic measurement bias in the absolute values for these ratios obtained by Chang et al. [1], more than any other effect (mass fractionation between "Sample 2" and IM-1009 can be ruled out since both were available in liquid form). Tanimizu et al. [9], from observations made about the mass discrimination behavior of their instrument, also concluded that the data from Chang et al. [1] seemed to be biased.

Besides, Figure 6 shows that the atomic weights determined over almost the last 60 years do not always coincide, and none of the published values falls in the range ( $a$ on Figure 6 ) endorsed by IUPAC [8]. It is well known [40] that $\mathrm{Zn}$ can easily be the subject of major isotopic fractionation effects during production (purification stages) that may explain, at least partially, the differences observed between the atomic weights of $\mathrm{Zn}$ materials measured over this period.

We measured three natural-like Zn materials $(c, d$, and $e$ in Figure 6). The value found for IRMM-651 is the smallest, possibly due to fractionation processes during the purification stage (distillation) carried out at EMPA. For IM-1009, consistently with the discrepancies observed for the isotope ratio values, there is a significant difference $(\sim 0.05 \%)$ with the atomic weight reported by Chang et al. [1] for their Sample 2 (a in Figure 6). The atomic weight of IRMM-3702 is similar within uncertainty to the values of other materials obtained from dissolved electrolytic zinc such as those measured in Tanimizu et al. [9] and Marinenko and Foley [7] ( $f$ and $l$ in Figure 6).

Finally, we recommend the atomic weight of $\mathrm{A}_{\mathrm{r}}$ $(\mathrm{Zn})=65.37777(22)$ obtained for IRMM-3702 (also known as "delta 0 " reference material) be considered by IUPAC as the standard atomic weight for this element.

\section{Acknowledgments}

The authors gratefully acknowledge P. Freedman for his supportive comments about this work and the manuscript.

\section{References}

1. Chang, T.-L.; Zhao, M.-T.; Li, W.-J. Wang, J.; Qian, Q.-Y. Absolute isotopic composition and atomic weight of zinc. Int. J. Mass Spectrom. 2001, 208, 113-118.

2. Stürup, S. Application of HR-ICP-MS for the simultaneous measurement of zinc isotope ratios and total zinc content in human samples. J. Anal. At. Spectrom. 2000, 15, 315-321.

3. Ingle, C. P.; Langford, N.; Harvey, L. J.; Dainty, J. R.; Turner, P. J.; Sharp, B. L.; Lewis, D. J. Comparison of three different instrumental approaches to the determination of iron and zinc isotope ratios in clinical samples. J. Anal. At. Spectrom. 2004, 19, 404-406.

4. Pichat, S.; Douchet, C.; Albarède, F. Zinc isotope variations in deep-sea carbonates from the eastern equatorial Pacific over the last $175 \mathrm{ka}$. Earth Planet. Sci. Lett. 2003, 210, 167-178.

5. Rosman, K. J. R.; Taylor, P. D. P. Isotopic compositions of the elements 1997. Pure Appl. Chem. 1998, 70, 217-235

6. Rosman, K. J. R. A survey of the isotopic and elemental abundance of zinc. Geochim. Cosmochim. Acta 1972, 36, 801-819.

7. Marinenko, G.; Foley, R. T. A new determination of the atomic weight of zinc. J. Res. Natl. Bur. Stand. 1971, 75A, 561.

8. Loss, R. D. Atomic weights of the elements 2001. Pure Appl. Chem. 2003, 75, 1107-1122.

9. Tanimizu, M.; Asada, Y.; Hirata, T. Absolute isotopic composition and atomic weight of commercial zinc using inductively coupled plasma mass spectrometry. Anal. Chem. 2002, 74, 5814-5819.

10. Maréchal, C. N.; Télouk, P.; Albarède, F. Precise analysis of copper and zinc isotopic compositions by plasma-source mass spectrometry. Chem. Geol. 1999, 156, 251-273.

11. Maréchal, C.; Albarède, F. Ion-exchange fractionation of copper and zinc isotopes. Geochim. Cosmochim. Acta 2002, 66, 1499-1509.

12. Mason, T. F. D.; Weiss, D. J.; Horstwood, M.; Parrish, R. R.; Russell, S. S.; Mullane, E.; Coles, B. J. J. High-precision $\mathrm{Cu}$ and $\mathrm{Zn}$ isotope analysis by plasma source mass spectrometry. Anal. At. Spectrom. 2004, 19, 209-217.

13. Galy, A.; Yoffe, O.; Janney, P. E.; Williams, R. W.; Cloquet, C.; Alard, O.; Halicz, L.; Wadhwa, M.; Hutcheon, I. D.; Ramon, E.; Carignan, J. J. Magnesium isotope heterogeneity of the isotopic standard SRM980 and new reference materials for magnesium-isotope ratio measurements. Anal. At. Spectrom. 2003, 18, 1352-1356.

14. IUPAC Technical Report. Isotope-abundance variations of selected elements. Pure Appl. Chem. 2002, 74, 1987-2017.

15. Catanzaro, E. J.; Murphy, T. J.; Shields, W. R.; Garner, E. L. Absolute isotopic abundance ratios of common, equal-atom and radiogenic lead isotopic standards. J. Res. Natl. Bur. Stand. 1968, 72A, 261-267.

16. Rosman, K. J. R.; Lycke, W.; Damen, R.; Werz, R.; Hendrickx, F.; Traas, L.; De Bièvre, P. The preparation and use of synthetic isotope mixtures for testing mass spectrometers. Int. J. Mass Spectrom. Ion Processes 1987, 79, 61-71.

17. Qi, H. P.; Berglund, M.; Taylor, P. D. P.; Hendrickx, F.; Verbruggen, A.; De Bièvre, P. Preparation and characterization of synthetic mixtures of lithium isotopes. Fresenius J. Anal. Chem. 1998, 361, 767-773.

18. Raptis, K.; Mayer, K.; Hendrickx, F.; De Bièvre, P. Preparation and certification of new thorium isotopic reference materials. Fresenius J. Anal. Chem. 1998, 361, 400-403.

19. Walder, A. J.; Freedman, P. A. Communication: Isotopic ratio measurement using a double focusing magnetic sector mass analyzer with an inductively coupled plasma as an ion source. J. Anal. At. Spectrom. 1992, 7, 571-575.

20. Russel, W. A.; Papanastassiou, D. A.; Tombrello, T. A. Ca isotope fractionation on the earth and other solar system materials. Geochim. Cosmochim. Acta 1978, 42, 1075-1090.

21. Freedman, P. A. Mass bias in ICP mass spectrometers. Goldschmidt Conference Abstracts 2002, A245. 
22. Snell, J. P.; Quétel, C. R. SI-traceable certification of methylmercury amount content in a tuna material. J. Anal. At. Spectrom. 2005, 20, 447-454.

23. Quétel, C. R.; Diemer, J. Different isotope ratio measurement applications for different types of ICP-MS: Comparative study of the performance capabilities and limitations. Handbook of Stable Isotope Analytical Techniques; de Groot, P. A., Ed.; Amsterdam, The Netherlands: Elsevier 2004, pp 726-745.

24. Belshaw, N. S.; Freedman, P. A.; O'Nions, R. K.; Frank, M.; Guo, Y. A new variable dispersion double-focusing plasma mass spectrometer with performance illustrated for Pb isotopes. Int. J. Mass Spectrom. 1998, 181, 51-58.

25. Nowell, G. M.; Pearson, D. G.; Ottley, C. J.; Schwieters, J.; Dowall, D. Long-term performance characteristics of a plasma ionization multicollector mass spectrometer (PIMMS): The ThermoFinnigan Neptune. Plasma source mass spectrometry. Spec. Pub. Royal Society of Chemistry 2003.

26. Marriott, P.; Fletcher, R.; Cole, A.; Beaumont, I.; Lofthouse, J.; Bloomfield, S.; Miller, P. Development of a new compact high resolution sector inductively coupled plasma mass spectrometer. J. Anal. At. Spectrom. 1998, 13, 1021-1025.

27. Fortunato, G. High vacuum distillation of metals. EMPA Standard Operating Procedure; 12/01/1999, SOP3286.

28. Fortunato, G. Purification of zinc. EMPA Standard Operating Procedure; 30/04/1999, SOP3287.

29. IRMM Catalog of certified isotopic reference materials available from http:/ / www.irmm.jrc.be/html/homepage.htm.

30. Hendrickx, F.; Bickel, M. Mass determination at the IRMM Analytical Chemistry Unit. Internal Report; 2003, GER/ACH/02/2003/March.

31. Nelms, S. M.; Quétel, C. R.; Prohaska, T.; Vogl, J.; Taylor, P. D. P. Evaluation of detector dead time calculation models for ICPMS. J. Anal. At. Spectrom. 2001, 16, 33-338.

32. International Organization for Standardization. Guide to the Expression of Uncertainty in Measurement; Geneva, Switzerland, 1995.

33. GUM Workbench, The Software Tool for the Expression of Uncertainty in Measurement; version 2.3.6, 2003; Metrodata GmbH: Grenzach-Wyhlen, Germany.
34. Kragten, J. Calculating standard deviations and confidence intervals with a universally applicable spreadsheet technique. Analyst 1994, 119, 2161-2165.

35. Quétel, C. R.; Prohaska, T.; Nelms, S. M.; Diemer, J.; Taylor, P. D. P. ICP-MS applied to isotope abundance ratio measurements: Performance study and development of a method for combining uncertainty contributions from measurement correction factors in Plasma Source Mass Spectrometry: The New Millennium. Proceeding of the 7th Durham Conference; Holland, G.; Tanner, S., Eds.; Royal Society of Chemistry: Cambridge, 2001; pp 257-269.

36. Quétel, C. R.; Vogl, J.; Prohaska, T.; Nelms, S.; Taylor, P. D. P.; De Bièvre, P. Comparative performance study of ICP mass spectrometers by means of U "isotopic measurements". Fresenius J. Anal. Chem. 2000, $368,148-155$

37. Vance, D.; Thirwall, M. An assessment of mass discrimination in MC-ICPMS using Nd isotopes. Chem. Geol. 2002, 185, 227-240.

38. Miller, J. N.; Miller, J. C. Statistics and chemometrics for analytical chemistry, 4th ed.; Harlow, UK: Pearson Education Limited 2000, pp $116-118$.

39. International Standard ISO/IEC 17025, 1st ed.; International Standards Organization: Geneva, Switzerland, 1999, p 13.

40. Hess, D. C.; Ighram, M. G., Jr.; Hayden, R. J. The relative abundances of the zinc isotopes. Phys. Rev 1948, 74, 1531-1532.

41. Leyland, W. T.; Nier, A. O. The relative abundances of the zinc and cadmium isotopes. Phys. Rev. 1948, 73, 1206.

42. Bainbridge, K. T.; Nier, A. O. Relative isotopic abundances of the elements. Preliminary Report, National Research Council; Washington, 1950; $\mathrm{p} 9$.

43. Hibbs, R. F. Mass spectrometric measurements of natural isotopic spectra. Report AECU-556; 1949.

44. Okamoto, J.; Kakuta, M.; Morito, N.; Nakajima, Y.; Tsuyama, H.; Onuki, H. Isotopic analysis of zinc with mass spectrometer. Jpn. Analyst 1959, 8, $445-449$.

45. Konishi, F.; Kusao, K.; Nakamura, N. On the photographic ion quantity measurement in the spark source mass spectrometry. Shitsuryo Bunseki. 1966, 14, 275-284. 